the reason for this peculiar phenomenon appears to be unknown.

It seems, however, to be purely transitory.

Lastly I think that, in the interests of the patients and for the sake of the reputation of the operation, fenestration ought only to be performed by surgeons already perfectly trained in aural surgery and with considerable experience of fenestration on the cadaver. It appears to me that professional ethics forbid the performance of this very specialized operation by surgeons who have not the necessary training.-I am, etc.,

Hôpital St. Antoine, Paris.

Paul Dubs.

\section{Cutaneous Cancer}

SIR.-Ycur leading article on the above subject (May 22. p. 986) recalls an experience which may amuse your readers. In the early summer of 1937 the Bill which became subsequently the great Factory Act of 1937 was considered in Standing Committee. The Committee consisted of 70 Members of Parliament drawn from all Parties, and for the greater part of its activities I was the only medical Member. There were 27 sessions of the Comnittee. The Bill bristled with medical problems, and, being the only Member with medical experience, I was a frequent speaker. Sir John Simon, as Home Secretary, was in charge of the Eill : my seat was directly behind his, and duologues between him and myself were constantly repeated. One of our most serious disagreements came over the schedule of industrial diseases subject to notification.

The Bill was a consolidating Bill, superseding all previous Factory enactments, whose purpose and effect would be to legislate for a generation to come ; the previous main Act was dated 1901. In that Act a number of diseases had been scheduled as notifiable the incidence of which had materially diminished in 36 years, and other diseases had assumed greater importance. I pointed out that phosphorus poisoning, notifiable in 1901, had almost ceased to exist in 1937, but cutaneous cancer showed a sharp upward curve of frequency. I contended that phosphorus poisoning should be omitted from the notifiable schedule and cutaneous cancer included, notification of which, I argued. would lead to earlier recognition and treatment and thus prevent the serious consequences which were frequent in overlooked or neglected cases. I was overruled with the argument that it was "administratively convenient" to transfer as many of the items as possible from the 1901 to the 1937 Schedule, and the Schedule of notifiable industrial diseases in the 1937 Act (vide Section 66) remains, as in 1901, restricted to "lead, phosphorus, arsenical or mercurial poisoning, or anthrax."-I am, etc..

House of Commons.

\section{E. Graham-Little.}

\section{Risks of Dicoumarol Therapy}

SIR,- In your annotation on the risks of dicoumarol therapy (May 22, p. 988) the work of Glueck and her colleagues ${ }^{1}$ is quoted on combined heparin-dicoumarol therapy in coronary thrombosis, the results in a treated series of 44 patients compared with 44 controls being as follows :

Thrombo-embolic complications

\begin{tabular}{ccc|c|c|c} 
& & & Present & Absent & Total \\
\hline Treated & $\ldots$ & $\ldots$ & 3 & 41 & 44 \\
Controls & $\cdots$ &.. & 12 & 32 & 44 \\
\hline Total &. & $\ldots$ & 15 & 73 & 88
\end{tabular}

\begin{tabular}{|c|c|c|c|c|}
\hline & & Died & Recovered & Total \\
\hline $\begin{array}{l}\text { Treated } \\
\text { Controls }\end{array}$ & $\begin{array}{ll}. & \ldots \\
\therefore & . .\end{array}$ & $\begin{array}{r}9 \\
20\end{array}$ & $\begin{array}{l}35 \\
24\end{array}$ & $\begin{array}{l}44 \\
44\end{array}$ \\
\hline Total & .. & 29 & 59 & 88 \\
\hline
\end{tabular}

It is then stated, "Though these figures may not satisfy statistical demands, it is only by the accumulation of the results of careful clinical studies that final decision will be reached on this important problem." Readers may be puzzled as to why significant differences are dismissed as not satisfying statistical demands, so it may be helpful to point out how the misconception has arisen, a misconception that is due to the authors of the paper rather than to the writer of the annotation, for he has simply quoted their conclusions.

In the body of the original paper the data referred to 25 treated patients and 25 controls, and among these neither of the differences shown above, though favourable to the treated, is significant, as is pointed out in the conclusions. A short addendum is then appended giving results for a further 19 treated patients and 19 controls, observed after the manuscript had been submitted. The authors, however, do not point out in the addendum that with the addition of these new results the previous conclusion as to the statistical significance of the differences requires modification.

Both the tables shown above give $\chi^{2}=5.143$ (using Yates's correction). Thus in both instances the chance of drawing two such diverse samples from a homogeneous population is no more than 1 in 43, the usual conventional level of statistical significance being 1 in 20 . The authors selected patients for the two series by the sound method of choosing alternate subjects for treatment. They remark in their conclusions (on the total of 50). "Although the series of cases is too small, and the variables of the disease itself too wide to make statistical analysis significant ..." This might be taken to imply that even if the restlts were significant they would still be doubtful, owing to the variability of the disease, as to whether differences might not be due to some accident in the selection of alternate patients rather than to the results of treatment. They have, however, tested a considerable number of variables, and scrutiny of their tables shows (in the first 50 at least) that none could account for the more favourable experience in the treated group. If then detailed analysis of the 38 additional patients yields the same results as the original series, it would seem that a good, though not of course overwhelming, case had been made out for the beneficial results of anticoagulant therapy.-I am, etc..

London, W.C.1

$$
\text { J. A. Fraser Roberts. }
$$

REFERENCE

1 Amer. Hecirt J., 1948, 35, 269.

\section{Peptic Ulceration}

SIR,-I am very glad to hear Mr. C. Jennings Marshall's approval of the analogy between the pains of chronic peptic ulcer and of chronic ulcer of the leg (March 13, p. 522), but I am sorry that he is dissatisfied and has reservations, seen in his question, "Surely the production of pain in the peripheral nervous system has a mechanism different from that in the viscera ?"Then again, it appears that he is dissatisfied with the secretory function as a middle term in the pain mechanism, so $\mathrm{h}$ ? selects the motor function. This is not very strong positive evidence in favour of his middle term and $I$ am sure he is dissatisfied with this position also. He rightly indicts the physicians (I would have added the physiologists) for not properly correlating the various factors. Mr. Jennings Marshall has shown a tendency to advance beyond old hypotheses. If he would only move a little further in the same direction he could rid himself of his dissatisfactions.

His first step must be to answer his own question. The nervous system is (to use the words which he applies to pathology) "one and indivisible." Surely, therefore, the production of pain in the peripheral nervous system has a mechanism no different from that in the visceral. There may be a quantitative difference because pain fibres are more sparse and less efficient in the viscera, but surely there is no essential difference.

Next. he insists that "food relationship of ulcer pain inevitably introduces gastric function as a middle term." Food relationship inevitably introduces gastric function, but not necessarily as a middle term. It only becomes necessary to introduce the awkward middle term if the stomach functions are conceived in terms of only a secretory and a motor system. But, if it be remembered that the stomach has in addition a functioning circulatory system, gastric function will be found already included in the first term. In the leg, the circumulcerous cellulitis and circulatory changes directly explain the pain, without the interposing of directly painful motor behaviour of the leg.

A further advantage of these forward steps is that $\mathrm{Mr}$. Jennings Marshall will find that his own favourite "most 